\title{
Beitrag zur Kenntnis der Labgerinnung.
}

Von

Dr. W. van Dam.

Mit drei Abbildungen.

(Der Redaktion zugegangen am 18. Dezember 1908.)

Es kommt hier und da vor, daß die Milch mancher Kühe regelmäßig oder von Zeit zu Zeit nicht oder nur schlecht nach Zusatz von Lab gerinnt. Um die Ursache dieser Erscheinung zu finden, wurden die nachstehenden Untersuchungen ausgeführt.

Es ist eine schon lange bekannte Tatsache, daß durch Zusatz löslicher Calciumsalze zu Milch deren Gerinnungsdauer bedeutend verkürzt wird. Setzt man nun diese Verbindungen nicht gerinnender Milch zu, dann kann man in der Regel wieder eine normal koagulierende Flüssigkeit bekommen. Daraus folgt also, daß die Ursache der Erscheinung sehr wahrscheinlich nicht auf Abweichungen in der Zusammensetzung der Milch in bezug auf Eiweiß, besonders Casein, zurückzuführen ist. Es lag nahe, ein Fehlen löslicher Kalksalze in dieser Milch anzunehmen, aber die früher von 0 tt de Vries und Boekhout ${ }^{1}$ ) ausgeführten Analysen sprechen nicht dafür, denn der Unterschied von den Zahlen, die für die normale Milch gelten, war so gering, daß die Abweichung diesem schwerlich zugeschrieben werden konnte.

Welche Veränderung vollzieht sich nun in der Milch nach Zusatz von Kalksalzen? Erstens wird, wie bekanni, aber nach meiner Ansicht noch nicht genügend erk]ärt ist, ${ }^{2}$ ) der Säure-

1) Landwirtsch. Versuchsstat., Bd. LV, S. 221 (1901).

2) Die Erklärung von de Jager, Tydschr. v. Gen. 1897, S. 253, halte ich für nicht genügend, so lange die Gleichgewichte der von ihm angegebenen Reaktionen nicht genau untersucht sind. 
grad, d. h. die Anzahl Kubikzentimeter Lauge von bestimmter Stärke, die nötig ist, um $100 \mathrm{ccm}$ Milch gegenüber Phenolphthalein zu neutralisieren, vermehrt. Zweitens wird ein Teil der Kalksalze in eine durch ein Chamberlandfilter nicht filtrierbare Form übergeführt.. ${ }^{1}$ ) Nach der allgemeinen Auffassung über den Gerinnungsprozeß kann dieser Teil aber nicht von Einfluß auf den Prozeß sein.

Meine Untersuchung ist nun in ihrem ersten Teil hauptsächlich eine Studie über den Säuregrad der Milch und den Zusammenhang, der zwischen ihm und der Gerinnungszeit besteht.

In der Milchchemie zog man bis jetzt nur den potenziellen Säuregrad in Betracht, $d$. h. die Menge Lauge, die für die Neutralisation eines bestimmten Volumens Milch nötig ist. Die Versuche, zwischen diesem und der Gerinnungszeit einen Zusammenhang zu finden, haben kein Resultat gezeitigt. Das ist nicht besonders auffällig, wenn man bedenkt, daß bei gleichem potenziellem Säuregrad zweier Flüssigkeiten der Gehalt an Wasserstoffionen, der aktuelle Säuregrad also, keinesfalls derselbe zu sein braucht. Nach den neueren Ansichten kann aber angenommen werden, daß, wenn die Acidität auf die Gerinnungszeit von Einfluß ist, es die Wasserstoffionen sind, die diesen Einfluß ausüben. Um bei der Suche nach einem Zusammenhang zwischen Säuregrad und Gerinnungszeit Aussicht auf Erfolg zu haben, mußte also der aktuelle Säuregrad bestimmt werden.

Von den verschiedenen Methoden, die man zur Bestimmung des H-Ionengehaltes einer Flüssigkeit anwenden kann, konnte in diesem Falle nur jene in Betracht kommen, bei der dieser Gehalt durch die Bestimmung der elektromotorischen Kraft einer Konzentrationskette gefunden wird; denn das ist die einzige, bei der die Milch völlig intakt bleibt. Zusatz von Chemikalien mußte vermieden werden. Die wenig günstigen Ergebnisse, die Höber ${ }^{2}$ ) bei Anwendung dieser Methode zur Bestimmung der Hydroxylionen im Blut erzielte, schreckten mich anfänglich davon ab. Auch lieferte das Verfahren von

1) Ott de Vries und Boekhout, loc. cit.

2) Pflügers Archiv, Bd. LXXXI, S. 522 (1900). 
Fraenkel $\left.{ }^{1}\right)$ mit Palladiumelektroden sehr unzulängliche Resultate, jedoch glückte es mir, nach einigem Experimentieren mit äußerst dünn platinierten Goldelektroden gute Resultate zu erzielen, und zwar in so kurzer Zeit, wie es für die geplante Untersuchung nötig war.

Ich gebrauchte die bekannte Kompensationsmethode Poggendorffs, wobei ein Dekadenrheostat und ein Leclanschéelement verwandt wurden, während ein vertikales Kapillarelektrometer als Nullinstrument diente. Standardelement war ein vor drei Jahren angefertigtes Westonelement. Da ich kein kontrolliertes Normalelement zur Verfügung hatte, machte ich mit Chemikalien einer anderen Fabrik ein zweites Weston, das von dem andern um 0,3 M. V. verschieden war. Die folgende Kette wurde gemessen:

H | 0,005 HCl | NaCl | Milch | $\mathrm{H}$.

Um die Flüssigkeitspotenziale soviel wie möglich zu vermeiden, wurde der Salzsäure ein Überschuß an Kochsalz zugesetzt, ${ }^{2}$ ) dessen Konzentration durch annähernde Berechnung der Ionenkonzentration aus der Leitfähigkeit des Milchserums bestimmt wurde. ${ }^{3}$ ) Für Milch ohne Zusatz von Chemikalien wie Salzsäure oder Lauge wurden $0,29 \% \mathrm{NaCl}$ gebraucht. Dadurch konnte die Ionenkonzentration aus der gefundenen elektromotorischen Kraft mit folgender vereinfachter Gleichung $\mathrm{E}=\mathrm{R} \mathrm{T} \cdot \log \frac{\mathrm{C}_{1}}{\mathrm{C}_{\mathrm{q}}}$ berechnet werden.

Um den Gehalt der Milch an Wasserstoff-Ionen zu ändern, wurde Salzsäure oder Lauge zugesetzt und in Übereinstimmung damit die Elektrolytkonzentration geändert. ${ }^{4}$ ) Durch wiederholte Messungen an ein- und derselben Probe überzeugte ich

1) Pflügers Archiv, Bd. XCVI, S. 601 (1905).

8) Nernst, Theoretische Chemie, 4. Aufl., S. 700.

s) Eigentlich hätte eine Mischung von Kaliumchlorid und Natriumchlorid gebraucht werden müssen, um eine Flüssigkeit $\mathrm{zu}$ bekommen, die soviel wie möglich mit dem Serum in osmotischem Gleichgewicht ist. Vergleichende Messungen zeigten mir jedoch, daß ohne Schwierigkeit Natriumchloridlösungen genommen werden konnten.

4) Bei Zusatz von Chlorcalcium oder Salzsäure zu der Milch wurde der Kochsalzlösung auch $\mathrm{CaCl}_{2}$ zugesetzt. 
mich natürlich von der vollständigen Übereinstimmung der Resultate untereinander, während obendrein von Zeit zu Zeit eine Bestimmung mit Salzsäure zur Kontrolle des ganzen Instrumentariums vorgenommen wurde.

Zur Feststellung, ob sich bei der nicht gerinnenden Milch eine Abweichung im Gehalt von H-Ionen zeigen würde, untersuchte ich Proben von verschiedenen Kühen der mit der hiesigen Versuchsstation verbundenen Versuchswirtschaft, um zu sehen, $z w i s c h e n$ welchen Grenzen sich die Konzentrationen bewegen.

Bei 12 Proben wurden die folgenden Werte gefunden:

$$
\text { Tabelle I. }
$$

H-Ionengehalt gut gerinnender Milch.

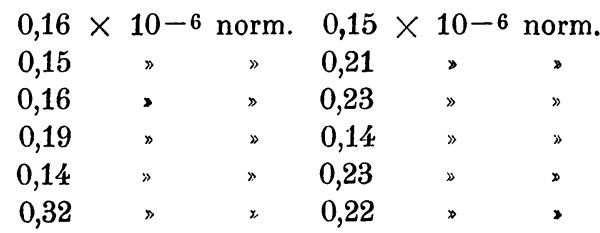

Diese Werte bewegen sich also zwischen 0,14 und $0,32 \times 10^{-6}$ Normalsäure; bei zwei Proben nicht gerinnender Milch wurden gefunden: 0,16 und $0,22 \times 10^{-6}$, woraus folgt, daß Mangel an H-Ionen nicht als die Ursache der abweichenden Eigenschaften dieser Proben angesehen werden kann.

Was die Größe selbst betrifft, so sieht man, daß sie sich dem Wasserstoff-Ionengehalt reinen Wassers, der bei $18^{\circ} \mathrm{C}$. $0,08 \times 10^{-6}$ norm. beträgt, nähert. Der aktuelle Säuregrad der Milch ist demnach ungefähr 100000 mal kleiner als der potenzielle.

Macht man sich nun eine Lösung von ungefähr gleichen Teilen 1/10-norm. Mono- und Binatriumphosphat, dann findet man in dieser Flüssigkeit ungefähr dieselbe Anzahl H-Ionen, die bei der Milch gefunden wurden. Daraus kann man aber keinen Schluß auf die Zusammensetzung des Serums ziehen, denn außer den Phosphaten sind noch andere Wasserstoffverbindungen teilweise dissoziiert, z. B. das Eiweiß.

Nach diesem Resultat lag es nahe, die Rolle, die die 
Kalksalze bei dem Gerinnen spielen, näher zu untersuchen; durch Zusatz von Chlorcalcium konnte nicht gerinnende Milch beinahe immer normal koagulierend gemacht werden. Die allgemeine Ansicht hierüber ist die, daß die Gerinnungszeit zunächst von der Menge der in der Milch aufgelösten Kalksalze abhängt. Reichel und Spiro ${ }^{1}$ ) kamen zu dem Schluß, daß nicht die Kalksalze als solche, sondern die Anzahl der Calcium-Ionen für die Zeit des Gerinnens maßgebend wäre (bei übrigens gleichen Verhältnissen natürlich). Das schnellere Gerinnen bei Zusatz von etwas Säure zu der Milch wurde daher auch den sich lösenden Kalksalzen zugeschrieben. ${ }^{2}$ ) Ott de Vries und Boekhout ${ }^{3}$ ) haben aber darauf hingewiesen, daß auch der Säuregrad als solcher eine Rolle spielt. Sie fanden nämlich, daß gekochte Milch, die einige Zeit mit Kohlensäuregas behandelt war, gut gerann, während nach dem Auspumpen des $\mathrm{CO}_{2}$ kein Gerinnen mehr eintrat. Der Gehalt an löslichen Kalksalzen war bei dem Auspumpen nicht nennenswert gefallen.

Vom physikalisch-chemischen Standpunkt aus scheint also aus diesem Experiment hervorzugehen, daß die H-Ionen die Labwirkung beeinflussen; dies ist eine auch bei andern Enzymen wahrgenommene Erscheinung. Bekannt ist z. B., daß die Schnelligkeit der Pepsinverdauung von Eiweiß von der Menge der H-Ionen abhängt.

Um also die Wirkung der Kalksalze bei dem Gerinnen näher kennen zu lernen, war es zunächst nötig, den Zusammenhang zwischen dem Gehalt an H-Ionen und Gerinnungszeit zu untersuchen. Hierbei ergibt sich aber die Schwierigkeit, daß man den Gehalt der Milch an H-Ionen nicht ändern kann, ohne gleichzeitig auch die Ca-Ionen in der Flüssigkeit zu ändern. Durch einen Kunstgriff glückte es mir, den durch die Änderung in der Menge der Ca-Ionen geübten Einfluß beinahe ganz auszuschalten. Schon im Jahre 1877 hat Hammarsten ${ }^{4}$ ) daraf

1) Hofmeisters Beiträge, Bd. VII, S. 478 (1905).

2) Söldner, Landw. Versuchsstat., Bd. XXXV, S. 352 (1888).

s) Ebenda.

4) Zur Kenntnis des Caseins und der Wirkung des Luabfermentes. 
hingewiesen, daß man bei dem Gerinnungsprozeß mit zwei wohl voneinander $\mathrm{zu}$ unterscheidenden Faktoren $\mathrm{zu}$ tun hat, nämlich der Umsetzung des Caseins in Paracasein und danach mit der Präzipitation des Paracaseinkalks, der Gerinnungserscheinung also, die wahrgenommen wird. Das letztere findet auch nach den Versuchen von Hammarsten nur statt, wenn Kalkverbindungen vorhanden sind; der erstere Uinsetzungsprozeß kann dagegen eintreten, auch wenn die Kalksalze völlig fehlen. Aus der Tatsache, daß das Gerinnen um so eher eintritt, je mehr Kalksalze vorhanden sind, zieht Hammarsten also den Schluß, daß die Kalksalze auch auf den fermentativen Prozeß Einfluß haben. Das braucht, glaube ich, keineswegs der Fall $\mathrm{zu}$ sein. Meiner Ansicht nach sagt Lörcher auf Grund seiner Untersuchungen ${ }^{1}$ ) ganz richtig:

«Daß die Kalksalze nur durch Ausfällung des Paracaseins beschleunigend wirken, ist durch diese Versuche nicht widerlegt; daß die Kalksalze den Prozeß der Umformung des Caseins durch Lab beschleunigen, nicht bewiesen. Da wir also nur bestimmt wissen, einmal, daß die Kalksalze (innerhalb gewisser Grenzen) die Labgerinnung beschleunigen, zum andern, daß sie bei der Ausfällung des Paracaseins beteiligt sind, weiter aber nichts, so hat die Hypothese, daß die Kalksalze durch ihre ausfällende Wirkung gerinnungsbeschleunigend wirken, am meisten für sich.»

Ich bin nun folgendermaßen zu Werke gegangen:

Von einer Probe gemengter Milch wurden einige Portionen durch Zusatz von Salzsäure und von Kaliumhydroxyd auf verschiedenen Gehalt an H-Ionen gebracht, und dabei achtete ich natürlich darauf, daß das Volumen bei allen dasselbe war; der Gehalt an löslichen Kalksalzen war dann also bei den verschiedenen Portionen nicht derselbe. Zunächst wurde nun so schnell wie möglich der Gehalt an H-Ionen in den verschiedenen Flüssigkeiten bestimmt. Da ich 5-6 Bestimmungen täglich machen konnte, war dies möglich, ohne fürchten $\mathrm{zu}$ müssen, daß eine Vermehrung der H-Ionen durch Bildung von Milchsäure eintreten würde. Um aber ganz sicher zu

1) Pflügers Archiv, Bd. LXIX, S. 141. 
gehen, wurde die zuerst untersuchte Flüssigkeit gegen Abend noch einmal behandelt, wobei nicht die geringste Vermehrung zu konstatieren war. Gleichzeitig wurden nun die Gerinnungszeiten bestimmt, aber nicht, wie es gewöhnlich geschieht, denn dann wäre es wegen des geänderten Gehaltes löslicher Kalksalze unmöglich gewesen, einen Schluß auf den Einfluß der H-Ionen zu ziehen. Um diese Schwierigkeiten zu vermeiden - schon oben wurde darauf hingedeutet -, wurde die Gerinnungszeit bestimmt bei einem großen Überschuß an löslichen Kalksalzen und zwar einem so großen, daß im Vergleich damit bei den durch Zusatz von $\mathrm{HCl}$ und $\mathrm{KOH}$ zubereiteten Proben der Gehalt an Kalksalzen sehr klein war. Das Lab wirkte aber auf die Portionen, denen noch kein Überschuß an Kalksalzen zugesetzt war. Nachdem die Wirkung einige Zeit gedauert hatte, war ein bestimmter Moment festzustellen, bei dem eine bestimmte Menge Chlorcalcium unmittelbar Präzipitation ergab, während dies ein paar Sekunden vorher nicht der Fall war.

Ein Beispiel mit den gefundenen Zahlen soll dies anschaulich machen.

Eine der Portionen, z. B. die, der so viel Salzsäure zugesetzt war, wie $10 \mathrm{ccm} 1 / 10$ norm. per $100 \mathrm{ccm}$ Milch entsprach (die Konzentrationen der Säure und der Lauge wurden so gewählt, daß $1 \mathrm{ccm}$ per $25 \mathrm{ccm}$ zugesetzt wurde, um zu starker Verdünnung vorzubeugen), wurde auf 6 bis 7 weite Röhren verteilt, die in einen Thermostaten von 0 stwald gestellt wurden. In jede Röhre wurden $25 \mathrm{ccm}$ pipettiert. Sechs andere Reagierröhren, in jeder $1 \mathrm{ccm}$ Lablösung, wurden ebenso in das Bad getan und nach einigen Minuten wurden die ersten $25 \mathrm{ccm}$ auf einmal in eine Röhre mit Lab gegossen (nicht umgekehrt!). Für die Wirkung wurden einige Sekunden - genau nach einem Chronometer berechnet - Zeit gelassen, dann der oben erwähnte Überschuß $\mathrm{CaCl}_{2}$ (in $1 \mathrm{ccm}$ aufgelöst) hineingeblasen und schließlich die Zeit bestimmt, welche von diesem Moment an bis zum Eintreten der Gerinnung verstrich. Dasselbe wurde nun mit der zweiten Röhre getan, wobei aber bis zum Zusetzen von $\mathrm{CaCl}_{2}$ etwas länger gewartet wurde, sodaß jetzt nach kürzerer Zeit die Gerinnung eintrat. Indem ich so fortfuhr, konnte 
schließlich der Zeitpunkt bestimmt werden, bei dem nach Zusatz des Chlorcalciums unmittelbar die Gerinnung sich zeigte.

1. Nach 20 "Labeinwirkung $\mathrm{CaCl}_{2}$ zugesetzt, Gerinnung nach 25 "

2. \40"

3. $>60^{\prime \prime}$

$4 .>70^{\prime \prime}$

$5 .>65 "$

$\Rightarrow$

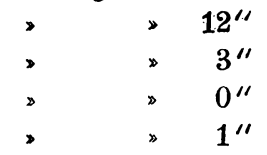

Nach 65-70" war also unter dem Einfluß des Labs der Zustand eingetreten, daß eine bestimmte $\mathrm{CaCl}_{2}$-Lösung das Paracasein unmittelbar fällte.

Genau so wurde nun bei den übrigen Portionen mit anderem H-Ionengehalt verfahren und dadurch wurde also der Einfluß der Kalksalze ausgeschaltet.

Die untenstehende Tabelle (II) gibt das Resultat an.

Tabelle II.

\begin{tabular}{|c|c|c|}
\hline Zusatz pro $100 \mathrm{ccm}$ Milch & $\mathrm{C} \cdot{ }_{\mathrm{H}} \times 10^{6}$ & $\mathrm{~T}$ (in Sekunden) \\
\hline $7,5 \mathrm{ccm} 1 / 10-\mathrm{n}-\mathrm{HGl}$ & 0,48 & $40-44$ \\
\hline $2,5>$ & 0,24 & $72-75$ \\
\hline $2,5>1 / 10-\mathrm{n}-\mathrm{KOH}$ & 0.12 & $145-150$ \\
\hline 10 & 0,034 & $400-410$ \\
\hline
\end{tabular}

Stellen wir dieses lie-

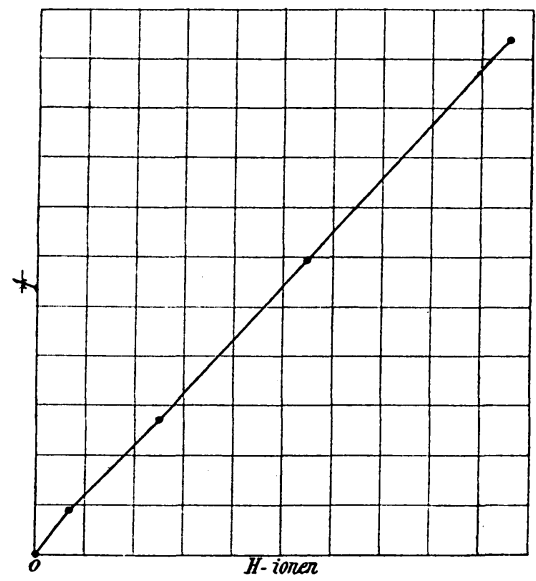

sultat graphisch dar, dann bekommen wir:

Wir finden also folgenden einfachen Zusammenhang: Die Gerinnungsgeschwindigkeit ist dem Gehalte an Wasserst off-Ionen, proportional, oder anders ausgedrückt: Die Gerinnungszeit ist umgekehrt proportional mit dem Gehalt an Wasserst off-Ionen. 
Diese Versuche wurden dreimal wiederholt, stets mit demselben Resultat. Es wurde jedoch - darauf sei hier noch einmal hingewiesen - von der Annahme ausgegangen, daß die geringe Menge gelöster Kalksalze in der Milch auf den Umsetzungsproze $\beta$ des Caseins von keinem Einfluß ist. Hierfür spricht noch das folgende. Wenn man die nach dem oben beschriebenen Verfahren bestimmten Gerinnungszeiten mit denen vergleicht, welche man bekommt, wenn direkt der Überschuß an $\mathrm{CaCl}_{2}$ zugesetzt wird, also vor der Vermischung mit Lab, dann ist ersichtlich, daß für die Milch mit höherem H-Ionengehalt der Unterschied in der Gerinnungszeit ungefähr Null ist; für geringe Konzentrationen ist dieser sehr groß, z. B.:

Tabelle III.

\begin{tabular}{lc|c|c}
\hline \hline $\begin{array}{c}\text { Per } 100 \mathrm{ccm} \text { Milch } \\
\text { zugesetzt }\end{array}$ & $\begin{array}{c}\mathrm{T} . \\
\text { Direkt } \mathrm{CaCl}_{2}(4 \% 0)\end{array}$ & Früher gefunden \\
\hline 1. $7,5 \mathrm{ccm} 1 / 10-\mathrm{n}-\mathrm{HCl}$ & $44^{\prime \prime}$ & $40-44$ \\
2. 2,5, &, & $50^{\prime \prime}$ & $72-75$ \\
3. $2,5,1 / 10-\mathrm{n}-\mathrm{KOH}$ & $56^{\prime \prime}$ & $145-150$ \\
4.10, & $68^{\prime \prime}$ & $400-410$
\end{tabular}

Es geht also daraus hervor, daß bei 1 kein nennenswerter Unterschied in der Gerinnungszeit wahrgenommen wurde; gleichgültig ist hier, ob man das Chlorcalcium vor der Labeinwirkung zusetzt oder später. Bei 2, 3 und 4 sieht man stets größere Unterschiede eintreten. Diese Erscheinung findet nun eine sehr einfache Erklärung dadurch, daß der Zusatz von $\mathrm{CaCl}_{2}$ den Gehalt an H-Ionen ändert, wie Tabelle IV zeigt.

Tabelle IV.

\begin{tabular}{c|c}
\hline \hline Zugesetzt $\mathrm{CaCl}_{2} \% 0$ & $\mathrm{G} \cdot \mathrm{H} \times 10^{6}$ \\
\hline 0 & 0,17 \\
0,1 & 0,18 \\
0,5 & 0,28 \\
1 & 0,34 \\
2 & 0,58
\end{tabular}

Hoppe-Seyler's Zeitschrift f. physiol. Chemie. LVIII. 
Bei Zusatz von $2 \% \mathrm{CaCl}_{2}$ sehen wir also, daß der $\mathrm{Ge}-$ halt an H-Ionen drei bis viermal größer wird. Dies ist jedoch nicht mehr der Fall, wenn vorher etwas $\mathrm{HCl}$ der Milch zugesetzt wird, wie die folgende Messung zeigt:

\section{'Tabelle V.}

\begin{tabular}{c|c|c|c|c}
\hline \hline $\begin{array}{c}\text { Zugesetzt 1/10-n-HCl } \\
\text { per 100 ccm Milch }\end{array}$ & $\begin{array}{c}\text { Tirekt } \\
\mathrm{CaCl}_{2} \\
2 \%\end{array}$ & $\begin{array}{c}\text { Später } \\
\mathrm{CaCl}_{2} \\
2 \%\end{array}$ & $\begin{array}{c}\mathrm{G} \cdot{ }_{\mathrm{H}} \times 10^{6} \\
\text { ohne } \mathrm{CaCl}_{2}\end{array}$ & $\begin{array}{c}\mathrm{G} \cdot{ }_{\mathrm{H}} \times 10^{6} \\
\mathrm{mit}_{\mathrm{CaCl}_{2}}\end{array}$ \\
\hline 0 & $36^{\prime \prime}$ & $73^{\prime \prime}$ & 0,16 & 0,51 \\
5 & $38^{\prime \prime}$ & $45^{\prime \prime}$ & - & - \\
15 & $24^{\prime \prime}$ & $26^{\prime \prime}$ & 1,13 & 1,63
\end{tabular}

Durch Zusatz des $\mathrm{CaCl}_{2}$ sehen wir also bei der nicht angesäuerten Milch den Gehalt an H-Ionen wieder drei- bis viermal größer werden, bei der angesäuerten Milch dagegen nur von 1,13 bis 1,63 steigen. Bei der Milch ohne $\mathrm{HCl}$ wirkt also das Lab in dem einen Falle in einem Medium mit dreibis viermal mehr H-Ionen als in dem andern; das erklärt den großen Unterschied in der Gerinnungszeit. Wenn $\mathrm{HCl}$ vorher zugesetzt ist, dann ist die relative Zunahme der H-Ionen durch Zusatz von $\mathrm{CaCl}_{2}$ klein, und wir sehen sich die Gerinnungszeiten einander nähern. Daß hier für Gerinnungszeit und H-Ionen keine umgekehrte Proportion gefunden wird, ist auch erklärlich.

Wie nämlich Zusatz von Kochsalz, Kaliumchlorid und anderen Salzen der Labwirkung entgegenwirkt, so kann man dasselbe von dem Chlorcalcium erwarten. So fand ich bei Milch, der $15 \mathrm{~cm}{ }^{1 / 10}-\mathrm{n}-\mathrm{HCl}$ per $100 \mathrm{ccm}$ zugesetzt war:

\section{Direkt $\mathrm{CaCl}_{2}(4 \% 00)$ :}

24 Sekunden.
Später:

20 Sekunden.

Hier - wo das Lab bei Vorhandensein von viel $\mathrm{CaCl}_{2}$ einwirkte, also bei höherem H-Ionengehalt - war die Gerinnungszeit deutlich länger als ohne jenen Zusatz. Der hemmende Einfluß des $\mathrm{CaCl}_{2}$ war hier stärker als der beschleunigende der H-Ionen.

Es ist unnötig, noch besonders zu besprechen, wie die bei 
anderen Untersuchungen ${ }^{1}$ ) erzielten Resultate sehr einfach durch obige Darlegung erklärt werden können. Nachdem einmal die Abhängigkeit des Gerinnungsprozesses von dem Gehalt an HIonen gefunden war, konnte näher untersucht werden, welche Rolle die löslichen Kalksalze spielen.

Ein paar vorläufige Proben ergaben mit Wahrscheinlichkeit, daß bei Zusatz von Säure zu der Milch die Beschleunigung des Gerinnens ausschließlich oder beinahe ausschließlich eine Folge der Veränderung der H-Ionen ist und also nicht oder so gut wie nicht von der Zunahme der löslichen Kalksalze herrührt. Es wurden folgende Versuche gemacht:

Eine Quantität Milch wurde in 5 gleiche Teile geteilt; jeder Portion wurde wieder eine bestimmte Menge $\mathrm{HCl}$ zugesetzt und der aktuelle Säuregrad zugleich mit der Gerinnungszeit bestimmt. Außerdem wurde noch von jeder Portion der lösliche Kalk- und Phosphorsäuregehalt festgestellt. (Warum das letztere getan wurde, ist weiter unten $\mathrm{zu}$ ersehen.) $\mathrm{Zu}$ diesem Zwecke wurde die Milch durch ein Chamberlandfilter unter einem Druck von 6 Atmosphären filtriert. Um $50 \mathrm{ccm}$ Filtrat zu bekommen, mußte drei Stunden lang filtriert werden, sodaß es nötig war, die verschiedenen Fläschchen in Eis aufzubewahren. 36 Stunden nach dem Melken war die letzte Menge filtriert. Von wahrnehmbarer Säurebildung war bei den getroffenen Vorsichtsmaßregeln nach jener Zeit noch nichts $\mathrm{zu}$ spüren. In Tabelle VI sind die Resultate zusammengestellt.

In der 4. Kolumne sind die Gerinnungszeiten angegeben und zwar berechnet aus den gefundenen Konzentrationen der H-Ionen unter der Annahme, daß die löslichen Kalksalze keinen Einfluß ausüben. Abgesehen von der höchsten Konzentration ist die Übereinstimmung ausgezeichnet.

Dies Resultal könnte aiso zu der Folgerung berechtigen, daß der Gehalt an löslichen Kalksalzen keinen Einfluß auf die Gerinnung ausübt; eine Auffassung also, die vollkommen der

1) Z. B. Arthus et Pagès, Arch. de Physiologie, Bd. XXII, S. 531 und 540. - Lörcher, Pflügers Arčhiv, Bd. LXIX, S. 141. 
Ansicht widerspricht, die man über die Rolle dieser Salze allgemein hat. ${ }^{1}$ )

Tabelle VI.

\begin{tabular}{|c|c|c|c|c|c|c|}
\hline \multirow{2}{*}{$\begin{array}{l}1 / 10-\mathrm{n}-\mathrm{HCl} \\
\text { per } \\
100 \mathrm{ccm} \\
\text { Milch }\end{array}$} & \multirow{2}{*}{$\mathrm{C}_{{ }_{H}} \times 10^{6}$} & \multicolumn{2}{|c|}{$\begin{array}{c}\mathrm{T} . \\
\text { (in Sekunden) }\end{array}$} & \multirow{2}{*}{$\begin{array}{l}\mathrm{mg} \mathrm{CaO} \\
\text { per } \\
100 \mathrm{ccm} \\
\text { Serum }\end{array}$} & \multirow{2}{*}{$\begin{array}{c}\mathrm{mg} \mathrm{P}_{2} \mathrm{O}_{5} \\
\text { per } \\
100 \mathrm{ccm} \\
\text { Serum }\end{array}$} & \multirow{2}{*}{$\begin{array}{c}\begin{array}{c}\text { Atome } \mathrm{Ca} \\
\text { aufgelöst }\end{array} \\
\begin{array}{c}\text { Molekül } \mathrm{P}_{2} \mathrm{O}_{5} \\
\text { aufgelöst }\end{array}\end{array}$} \\
\hline & & Gef. & Ber. & & & \\
\hline 0 & 0,16 & 145 & - & 48 & 88,6 & - \\
\hline 5 & 0,40 & 56 & 58 & 61,4 & 107 & $1,8: 1$ \\
\hline 10 & 0,67 & 33 & 35 & $-2)$ & $-2)$ & $-2)$ \\
\hline 15 & 1 & 23 & 23 & 83,8 & 123 & $2,7: 1$ \\
\hline 20 & 1,73 & 22 & 13 & 101,1 & 131 & $3,2: 1$ \\
\hline
\end{tabular}

Die hier mitgeteilten Resultate bilden aber meiner Meinung nach ein so starkes Argument gegen diese Auffassung, daß ich mich genötigt sah, die Gründe, welche dafür angeführt werden, einen nach dem andern näher zu untersuchen.

1. Zusatz von Chlorcalcium zu Milch verkürzt beträchtlich die Gerinnungszeit.

Durch diese Tatsache schon allein ist man dazu gekommen, in den löslichen Kalksalzen die Ursache davon zu sehen. So sind, wie schon gesagt wurde, Reichel und Spiro ${ }^{3}$ ) auf Grund einer ausführlichen Untersuchung zu dem Schluß gekommen, daß die Gerinnungszeit eine Funktion des Gehaltes an Calciumionen ist. Sie gingen auf folgende Weise zu Werke.

Einem bestimmten Volumen Milch wurde $1 \mathrm{ccm} \mathrm{CaCl}{ }_{2}$ Lös. von verschiedenen Konzentrationen zugesetzt und die Gerinnungszeit bestimmt, wobei die in Tabelle VII angegebenen Werte gefunden wurden.

In der dritten Kolumne sind die Werte des Produktes $(\mathrm{p}+0,6) \mathrm{T}$., worin $\mathrm{p}=\mathrm{CaCl}_{2}-$ Gehalt und $\mathrm{T}$. die Gerinnungszeit ist, angegeben. Wie man sieht, ist dies Produkt für nicht

1) Eine ausgezeichnete Übersicht über den Gegenstand gibt Fuld, Ergebnisse der Physiologie, Bd. I (1902), S. 468.

2) Analyse mißlungen.

3) Ebenda, vgl. auch Arrhenius, Immuno-chemie, S. 48. 
zu hohe Konzentrationen ungefähr konstant. Die Zahl 0,6, die $p$ hinzugefügt werden muß, um die konstanten Werte zu bekommen, muß dann nach den genannten Untersuchungen aufgefaßt werden als die Menge Calcium-Ionen (als $\mathrm{CaCl}_{2}$ berechnet), die in der Milch, ohne Zusatz von $\mathrm{CaCl}_{2}$, vorhanden sind.

Tabelle VII.

\begin{tabular}{c|c|c}
\hline $\mathrm{CaCl}_{2} \% 0$ & T. (in Sekunden) & $(\mathrm{p}+0,6) \mathrm{T}$. \\
\hline 0 & 48 & 28,8 \\
0,05 & 45,6 & 29,6 \\
0,1 & 41,6 & 29,1 \\
0,2 & 36 & 28.8 \\
0,5 & 26,4 & 29,0 \\
1 & 18,2 & 29,1 \\
2 & 11 & 28,6 \\
5 & 7,4 & 41,4 \\
10 & 9,2 & 97,5 \\
20 & 15 & 309
\end{tabular}

Bei der Annahme eines löslichen $\mathrm{CaO}-$ Gehaltes von 0,08\% (nach Söldner) wären 37\% der Kalksalze dissoziiert. ${ }^{1}$ ) Nimmt man die von Reichel und Spiro selbst angegebene Zahl, nämlich $0,05 \%,{ }^{2}$ ) dann werden $60 \%$ gefunden.

Stellt man ihr Resultat graphisch dar, dann bekommt man folgende Linie (s. Fig. auf S. 308).

Reichel und Spiro schließen daraus also:

Die Gerinnungszeit ist umgekehrt proportional dem Gehalt an Calcium-Ionen.

1) Reichel und Spiro geben $60 \%$ an. Das muß auf einem Irrtum beruhen, denn in der Abhandlung von Söldner, Versuchsstation 35 (seine Dissertation war mir nicht zur Verfügung) fand ich die oben angegebene Zahl $0,08 \% \mathrm{CaO}$.

2) Die Zahl von Söldner ist die höchste, die in der Literatur vorkommt. Duclaux, Ott de Vries und Boekhout geben übereinstimmend $0,05 \%$. Diese Zahl habe ich selbst wiederholt gefunden. 
Hierbei wird aber nicht mit der Tatsache gerechnet, daß von dem der Milch zugesetzten Chlorcalcium ein Teil in unlöslichen Zustand übergeht; bei diesem Teil kann also nicht mehr von Ionen gesprochen werden.

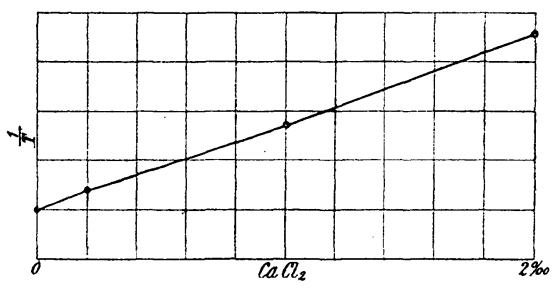

Zweitensändert sich der H-Ionengehalt in der Flüssigkeit: auch das müßte in Betracht gezogen werden.

Der Schluß, den diese Forscher ziehen, ist also nicht gerecht-

fertigt. Der regelmäßige Verlauf der von ihnen gefundenen Linie ist aber kaum einem Zufall zuzuschreiben. Um über ihr Resultat mir Klarheit zu verschaffen, habe ich untersucht, welcher Teil des zugesetzten Chlorcalciums bei den verschiedenen von ihnen gebrauchten Konzentrationen in die unlösliche Form übergeht. Dazu wurden wieder einige Portionen von derselben Milchprobe mit verschiedenen Mengen $\mathrm{CaCl}_{2}$ vermengt, so schnell wie möglich durch ein Chamberlandfilter filtriert und in dem Filtrat der Kalkgehalt bestimmt.

Durch ein paar Proben überzeugte ich mich, daß das Chlor quantitativ in das Serum übergeht. Tabelle VIII gibt die Resultate an.

Tabelle VIII.

\begin{tabular}{c|c|c|c}
\hline$\% \mathrm{CaCl}_{2}$ & $\begin{array}{c}\text { mg CaO per } \\
100 \text { Serum }\end{array}$ & $\begin{array}{c}\text { Festgelegt CaO } \\
\text { per 100 Serum }\end{array}$ & $\begin{array}{c}\text { Festgelegte \%o von } \\
\text { zugefügtem } \mathrm{CaCl}_{2}\end{array}$ \\
\hline 0 & 48,0 & - & - \\
0,5 & 66,0 & 7,0 & $\tilde{5} 6,0$ \\
1,0 & 72,8 & 25,2 & 50,4 \\
1,5 & 83,7 & 39,3 & 52,4 \\
2,0 & 108,0 & 40,0 & 40,0
\end{tabular}

Aus dieser Tabelle ist also ersichtlich, daß $\pm 50 \%$ des 
zugesetzten Chlorcalciums in den unlöslichen Zustand übergeht. Auf welche Weise die Calcium-Ionen gebunden werden, ist nicht mit Sicherheit zu sagen, aber es liegt auf der Hand, eine teilweise Bindung an das Casein anzunehmen. Auffallend ist noch, daß bei den höheren Konzentrationen $\frac{\mathrm{v}}{\mathrm{h}} \mathrm{CaCl}_{2}(2 \%)$ beinahe nicht mehr Calciumionen gebunden werden, als für die Menge von 1,5\% I Ich komme noch darauf zurück.

Setzt man dem Serum Chlorcalcium zu, dann entsteht eine Trübung; es schien mir wichtig, zu untersuchen, wieviel $\mathrm{CaO}$ auch in diesem Falle festgelegt wurde, damit ich über die Menge, die von den kolloidal gelösten Stoffen der Milch gebunden wird, auch näheren Aufschluß bekam. Bei den kleineren Konzentrationen aber (0,5 und 1) war die Flüssigkeit von dem Niederschlag nicht zu trennen; die Abscheidung war sehr gering. Bei 1,5 und $2 \%$ wurde niedergeschlagen $\mathrm{CaO}$ per 100 Serum resp. 15 und $20 \mathrm{mg}$. Hierdurch ist aber noch keineswegs festgestellt, daß bei Zusatz des $\mathrm{CaCl}_{2}$ zu der Milch auch 15 und $20 \mathrm{mg} \mathrm{CaO}$ auf Rechnung des Serums kommen.

Bei der «Oxalatmilch», von der später die Rede ist, wird dies näher erläutert; die größte Menge des festgelegten $\mathrm{CaCl}_{2}$ ist wahrscheinlich an das Casein gebunden.

Zieht man dieses Resultat in Betracht, dann ist ersichtlich, daß die Schlüsse von Reichel und Spiro schon allein deswegen nicht richtig sind, noch ganz abgesehen von der Veränderung der Wasserstoff-Ionen. Aber außerdem geht daraus hervor, daß durchaus nicht aus der Tatsache, daß durch Zusatz von Ghlorcalcium zu Milch die Gerinnungszeit verkürzt wird, geschlossen werden kann, diese Beschleunigung wäre eine direkte Folge der Vermehrung der löslichen Kalksalze.

Sieht man von den anderen Argumenten, die für die Hypothese der löslichen Kalksalze angeführt werden, $a b$, dann kann ganz gut die schnellere Gerinnung dem Umstande zugeschrieben werden, daß das Casein mit einer Kalkmenge, die größer ist, als wie sie in der ursprünglichen Milch vorhanden war, in Verbindung tritt. Diese Annahme ist ebenso berechtigt wie die, welche von der Vermehrung der löslichen Kalksalze 
ausgeht. Hierbei ist es noch wichtig, darauf hinzuweisen, daß, wie wir oben sahen, über eine bestimmte Konzentration von Chlorcalcium hinaus keine Calcium-Ionen mehr gebunden werden; auffallend ist, daß dies gerade die Konzentration betrifft, von der in der Linie von Reichel und Spiro die Abweichung von der Geraden sich zu zeigen anfängt.

Ferner muß hier noch auf eine Besonderheit in Tabelle VI S. 306 hingewiesen werden. In der 5. und 6. Kolumne ist angegeben, wieviel $\mathrm{CaO}$ und $\mathrm{P}_{2} \mathrm{O}_{\overline{5}}$ in dem Serum der mit Salzsäure angesäuerten Milch vorkommt, und die 7. Kolumne zeigt, wieviel Atome Calcium gegen $1 \mathrm{Mol} . \mathrm{P}_{2} \mathrm{O}_{5}$ aufgelöst sind. Während für 5 und $15 \mathrm{ccm} 1 / 10-\mathrm{n}-\mathrm{HCl}$ das Verhältnis $1: 1,8$ und $1: 2,7$ gefunden wurde, lieferte der Zusatz von $20 \mathrm{ccm}$ 1/10-n-HCl schon $1: 3,2$. In diesem letzteren Falle müssen also Calciumatome sich aufgelöst haben, welche nicht an Phosphorsäure gebunden waren. Wahrscheinlich ist hier der Caseinkalk angegriffen, und dann wäre hierdurch zusammen mit dem oben Angeführten die Abweichung vollkommen erklärt, die in diesem Falle für die gefundene und berechnete Gerinnungszeit wahrgenommen wurde. Daß die hier festgestellte Verzögerung durch die oben besprochene hemmende Wirkung des Chlorcalciums in höherer Konzentration verursacht worden ist, ist nicht anzunehmen; ist doch $20 \mathrm{ccm} 1 / 10-\mathrm{n}-\mathrm{HCl}$ per $100 \mathrm{ccm}$ Milch äquivalent mit $1,11 \mathrm{CaCl}_{2} \%$.

Diese beiden Tatsachen stützen also obige Auffassung.

Schließlich haben die Untersuchungen von Reichel und Spiro mich dazu gebracht, eine direkte Bestimmung der Dissoziation der Kalksalze in Serum zu machen. Natürlich können im allgemeinen die für eine Probe Milch gefundenen Zahlen nicht direkt mit denen, welche ein anderes Produkt lieferte, verglichen werden, aber die von mir gefundenen Werte weichen so erheblich von denen ab, zu denen Reichel und Spiro auf einem Umweg gekommen sind, daß es mir wichtig scheint, auch diesen Teil meiner Untersuchung hier kurz mitzuteilen.

Hierbei wurde von folgendem Gedankengang ausgegangen.

Wenn ein elektrischer Strom durch Milchserum geleitet wird, dann findet der. Transport der Elektrizität durch die in 
dem Serum vorhandenen Ionen statt; die nicht dissoziierten Verbindungen tragen nicht dazu bei. Hiermit geht aber eine Konzentrationsänderung an den Elektroden zusammen. Wenn also nach dem Durchgang des elektrischen Stromes an der negativen Elektrode eine Konzentration von Calcium gefunden würde, die größer wäre als vor dem Versuch, dann wäre dies ein Beweis für die Dissoziation der Kalksalze in dem Serum, aber außerdem könnte aus der gefundenen Konzentrationsänderung das Maß der Dissoziation annähernd berechnet werden, wenn gleichzeitig der Kaliumgehalt vor und nach dem Versuch bestimmt wurde.

In eine Röhre in der Form eines doppelten U (siehe Figur) wurden $\pm 200 \mathrm{ccm}$ Serum gegossen und zwei Platina-Elektroden in die offenen Schenkel in der Weise, wie es in der Figur angegeben ist, eingeführt. Die Gasentwicklung an den Elek-

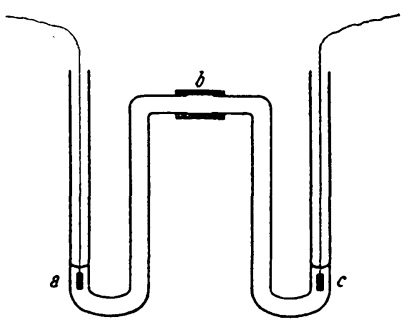
troden wirkte also in keiner Hinsicht störend. Die Länge der Flüssigkeitslinie $\mathrm{a}, \mathrm{b}, \mathrm{c}$ betrug $80-85 \mathrm{ccm}$, wodurch die Sicherheit gewährleistet wurde, daß die Lösung bei $b$ nach der Elektrolyse unverändert geblieben war. Bei einer Polspannung von $220 \mathrm{~V}$. wurde 2-3 Stunden elektrolysiert; die Stromstärke betrug 25-30 M. A. Nach Ablauf der Elektrolyse wurde die Flüssigkeitslinie bei $b$ in zwei Teile geteilt und die Kathodenflüssigkeit so sorgfältig wie möglich analysiert. Durch gleichzeitige Analyse desselben nicht elektrolysierten Serums konnte bestimmt werden, wieviel Kalium- und Calcium-Ionen transportiert waren. Gefunden wurde z. B.:

Vor der Elektrolyse: $0,319 \mathrm{~g} \mathrm{KCl}$ und 0,0505 $\mathrm{g} \mathrm{CaO}$ per 102,75 g Serum. Nach s

Transportiert: $0,086 \mathrm{~g} \mathrm{KCl}$ und 0 g CaO.

Unter der Annahme, daß die Kaliumsalze in der Milch vollständig dissoziiert sind, ${ }^{1}$ ) müßten bei ebenfalls vollständiger

1) Dies ist sicher nicht der Fall, wie aus der Leitfähigkeit des 
Dissoziation der Kalksalze und in Anbetracht des Unterschiedes in der Schnelligkeit des Transportes des Kalium- und CalciumIons, wie es für wässerige Lösungen bekannt ist, $12,3 \mathrm{mg} \mathrm{CaO}$ transportiert sein.

Eine zweite Bestimmung ergab hiervon abweichende Zahlen, nämlich transportiert $\mathrm{CaO}-2,2 \mathrm{mg}$. Bei vollständiger Dissoziation der Kalksalze hätten $7 \mathrm{mg}$ transportiert sein müssen, sodaß hieraus auf eine Dissoziation von $\frac{220}{7}=31 \%$ geschlossen werden müßte. Diese Bestimmung verdient aber wenig Vertrauen, da nur $51 \mathrm{mg} \mathrm{KCl}$ transportiert waren. ${ }^{1}$ )

Bei einer dritten Bestimmung, wobei $91 \mathrm{mg} \mathrm{KCl}$ transportiert wurden, wurde gefunden : - 0,7 mg. CaO transportiert gegen $12,7 \mathrm{mg}$ bei vollständiger Dissoziation. Aus diesen Versuchen kann man wohl schließen, daß die Dissoziation der Kalksalze äußert gering ist, sicher nicht mehr als $10-12 \%{ }^{2}$ ) Wie man sieht, ist der Unterschied gegenüber den durch Reichel und Spiro gefundenen Zahlen so groß, daß auch hiernach ihre Schlußfolgerungen als nicht richtig angesehen werden können.

Zugleich ging hieraus hervor, daß es keinen Zweck hat, den Versuch auch mit nicht gerinnender Milch zu machen, wie es anfänglich meine Absicht war, da ich die Ursache in dem Mangel an Calcium-Ionen bei dieser Milch suchte.

2. Durch Zusatz von einem löslichen Oxalat zu Milch gerinnt diese nicht.

Diese Erscheinung ist immer ein starkes Argument für die Wirkung der löslichen Kalksalze gewesen. Denn, so schließt man, durch die Oxalat-Ionen wird das Calcium präzipitiert und

Milchserums hervorgeht. Vgl. z. B. van der La an, "Chemisch-Physische onderzoekingen over de samenstelling der melk» (Utrecht 1896) und Hans Koeppe, Vergleichende Untersuchungen über die Salze der Frauen- und Kuhmilch (Dissertation).

1) Diese Bestimmungen wurden hier in dem Maschinenraum der Fabrik für kondensierte Milch vorgenommen, wobei es etwas schwierig war, die günstigsten Verhältnisse zu wählen.

2) Dabei ist angenommnn, daß bei der Analyse höchstens $1,5 \mathrm{mg}$ $\mathrm{CaO}$ zu wenig per $100 \mathrm{~g}$ gefunden werden kann. 
damit ist die Möglichkeit verschwunden, daß das Gerinnen eintreten kann.

Da die obigen Versuche meinen Glauben an die Richtigkeit dieser Auffassung stark erschüttert hatten, machte ich folgenden Versuch.

Einer Milchprobe wurde soviel Kaliumoxalat zugesetzt, als gerade genügte, um die gelösten Kalksalze als Calciumoxalat niederzuschlagen. Diese Milch war ungerinnbar. Nach ein paar Stunden wurde durch ein Chamberlandfilter filtriert und in dem Filtrat das noch vorhandene Calcium bestimmt. Man sollte erwarten, kein Calcium oder nur Spuren davon zu finden. Das Resultat war aber anders.

Per $100 \mathrm{ccm}$ Serum der ursprünglichen Milch $50 \mathrm{mg} \mathrm{CaO}$.

, $100 \gg \gg$ Oxalatmilch

38 >

Dieser Versuch wurde mit durchaus demselben Resultat wiederholt. Das zugefügte Kaliumoxalat scheint sich über die normal gelösten und die kolloidal vorhandenen Kalksalze zu verteilen. In beiden Fällen schlugen sich nur $12 \mathrm{mg} \mathrm{CaO}$ von den 50 nieder, sodaß $38 \mathrm{mg}$ gelöst blieben. Der größte Teil der Oxalat-Ionen bemächtigt sich also des nicht normal gelösten Calciums; das Serum der Oxalatmilch ist vollständig frei von 0 xalat.

Wie gesagt, diese Milch gerinnt nicht, obwohl noch $38 \mathrm{mg}$ $\mathrm{CaO}$ gelöst sind.

Ferner wurde der Oxalatmilch, die also nicht mehr gerann, noch Chlorcalcium zugesetzt, um sie zu regenerieren, und dann der Gehalt an löslichen Kalksalzen und die Gerinnungszeit bestimmt.

$100 \mathrm{ccm}$ Serum enthalten 48,6 mg $\mathrm{CaO} . \mathrm{Zu} 104 \mathrm{ccm}$ Milch (= 100 Serum) zugesetzt $0,160 \mathrm{~g} \mathrm{~K}_{2} \mathrm{C}_{2} \mathrm{O}_{4} 1$ aq., das ist die mit $0,0486 \mathrm{~g} \mathrm{CaO}$ äquivalente Menge.

Gerinnungszeit ursprünglicher Milch 90" (s. Tab.IX, S. 314).

Sehen wir diese Tabelle nun genauer an, dann finden wir, daß in der Oxalatmilch ohne Zusatz von $\mathrm{CaCl}_{2}$, die also nicht gerinnt, $39 \mathrm{mg} \mathrm{CaO}$ aufgelöst sind, daß also auch $39 \mathrm{mg} \mathrm{CaO}$ des kolloidalen Kalkes präzipitiert sein müssen. Aus der zweiten Horizontalen lesen wir $a b$, daß der ganze Zusatz von Chlorcalcium (25 mg $\mathrm{CaO}$ ) festgelegt ist. 
Tabelle IX.

\begin{tabular}{c|c|c|c|c}
\hline $\begin{array}{c}\text { Zugesetzt } \\
\mathrm{CaCl}_{2} \% \mathrm{zu} \\
\text { oxal. Milch }\end{array}$ & $\mathrm{T}$. & $\begin{array}{c}\text { Aufgelöst } \\
\mathrm{mg} \mathrm{CaO} \text { in } \\
100 \text { Serum }\end{array}$ & $\begin{array}{c}\text { Festgelegt CaO } \\
\text { durch kolloidale } \\
\text { Verbindungen } \\
\text { von 100 Milch }\end{array}$ & $\mathrm{G} \cdot \mathrm{H} \times 10-6$ \\
\hline 0 & $\infty$ & 39 & - & 0,13 \\
0,5 & $<1$ Std. & 38 & 25 & - \\
0,75 & $360^{\prime \prime}$ & 40 & 37 & - \\
1,0 & $85^{\prime \prime}$ & 48 & 40 & 0,15
\end{tabular}

Von den $39 \mathrm{mg}$, die als Oxalat präzipitiert waren, sind also $25 \mathrm{mg}$ wieder aufgenommen. Nach einer Stunde war diese Milch noch nicht geronnen.

Aus der dritten Reihe ist ersichtlich, daß wieder beinahe das ganze hinzugesetzte Chlorcalcium festgelegt ist (40 mg aufgelöst gegen 39 in der nicht behandelten Milch), und jetzt gerinnt diese Milch wieder ganz regelrecht; aber noch nach längerer Zeit als die nicht behandelte Milch. Die Oxalatmilch ohne Zusatz, die auf $1 \mathrm{mg} \mathrm{CaO}$ noch denselben Gehalt an löslichen Kalkverbindungen hat, ist vollkommen ungerinnbar. In der letzten Reihe finden wir den ursprünglichen Zustand der Milch beinahe wieder hergestellt.

Zum Schlusse machte ich noch folgenden Versuch. Einem Teil einer Milchprobe wurde wieder eine mit den gelösten Kalksalzen äquivalente Menge Kaliumoxalat zugesetzt; von einem andern Teil wurden $100 \mathrm{ccm}$ in einen Dialysator gebracht und gegen wiederholt erneuertes destilliertes Wasser 24 Stunden lang dialysiert. Das Dialysat wurde eingedampft und der Kalk darin bestimmt. Die Milch aus dem Dialysator, die aber von 100 auf 140 verdünnt war, wurde auf die Gerinnungszeit untersucht. $\mathrm{CaO}$ per 100 Serum ursprüngl. Milch $49,6 \mathrm{mg}$.

$$
\text { > } 100 \text { >xalatmilch 37,7 * }
$$

Nach 6 Stunden war die Oxalatmilch nicht geronnen.

$\mathrm{CaO}$ im Dialysat $29,3 \mathrm{mg}$. Nach $\mathbf{1}^{1 / 2}$ Stunden deutliches Gerinnen der dialysierten Milch. (Die Gerinnungszeit ist also sicher kürzer gewesen, wurde aber nicht genau bestimmt.) 
Hier sehen wir also, daß die Milch mit $38 \mathrm{mg}$ löslicher Kalksalze, wovon aber der Caseinkalk wahrscheinlich angetastet ist, nicht gerinnt, während dieselbe Milch, deren löslicher Kalkgehalt durch Diffusion auf $\frac{100}{140} \times 20,3=14,5 \mathrm{mg} \mathrm{CaO}$ gebracht wurde, noch sehr gut zum Koagulieren zu bringen ist. (Hierbei ist angenommen, daß bei der Diffusion kein $\mathrm{CaO}$ von dem pseudo-löslichen Zustand in normal gelöste $\mathrm{CaO}$ übergegangen ist. Vermutlich ist dies bei einem sehr kleinen Teile aber doch der Fall.)

Fassen wir diese Resultate zusammen, dann ist ersichtlich, daß das Nichtgerinnen der Oxalatmilch viel mehr ein Argument für die oben dargelegte Auffassung ist als für die Hypothese, $\mathrm{da} ß$ die löslichen Kalksalze in erster. Linie eine Rolle spielen.

Die Annahme lag allzu nahe, daß bei Zusatz von Ammoniumoxalat in erster Linie die normal gelösten Kalkverbindungen angegriffen werden müßten, aus meinen Ergebnissen geht aber deutlich hervor, daß dies nicht der Fall ist.

3. Durch Zusatz eines löslichen Citrats wird die Gerinnungszeit beträchtlich verlängert.

Auch hier ergaben meine Untersuchungen, daß die bestehende Auffassung nicht richtig ist. Man nimmt an, daß durch Zusatz von Kaliumcitrat $z$. B. die Kalksalze niedergeschlagen werden, wie durch Ammoniumoxalat, da Calciumcitrat in Wasser schwer löslich ist. Das Gegenteil ist der Fall. Kaliumcitrat hat die Eigenschaft, die Kalksalze der Milch aufzulösen, und trotzdem sehen wir die Gerinnungszeit größer werden. Auch hier habe ich bestimmt, wieviel Atome Ca auf 1 Mol. $\mathrm{P}_{2} \mathrm{O}_{5}$ aufgelöst werden, und wie aus Tabelle $\mathrm{X}$ ersichtlich ist, muß wieder ein Teil des an Casein gebundenen Kalkes aufgelöst werden. Durch ein paar Messungen der H-Ionen wurde konstatiert, daß nicht eine Veränderung dieser der Grund des langsameren Gerinnens sein konnte.

Dieses Resultat läßt sich auf keinen Fall mit der Behauptung in Einklang bringen: je mehr lösliche Kalksalze, desto schnelleres Gerinnen. Nimmt man die Calcium-Ionen als die Ursache davon an, dann könnte man ebensogut dies Resultat 
so erklären, daß durch Zusatz des Kaliumcitrats die Dissoziation des Calciumcitrats, das in der Milch vorhanden zu sein scheint, zurückgedrängt wird, wodurch schließlich in der Citratmilch doch weniger Ca-Ionen vorhanden sein würden, als in der ursprünglichen, obwohl sie mehr gelöste Kalksalze enthält. Über die Dissoziation von Calciumcitrat ist aber in der Literatur keine Angabe $z u$ finden. Messungen über die Leitfähigkeit sind $\mathrm{zu}$ diesem Zwecke unternommen, aber a priori ist wohl zu sagen, daß die Ergebnisse für wässerige Lösungen nicht einfach auf die Milch zu übertragen sind.

Tabelle X.

\begin{tabular}{|c|c|c|c|c|c|c|}
\hline & $\begin{array}{c}\text { Zusatz } \\
\text { K. citr. } \\
0 / 00\end{array}$ & T. & $\begin{array}{c}\mathrm{mg} \mathrm{CaO} \\
\text { per } 100 \\
\text { Serum }\end{array}$ & $\begin{array}{c}\mathrm{mg} \mathrm{P}_{2} \mathrm{O}_{5} \\
\text { per } 100 \\
\text { Serum }\end{array}$ & $\begin{array}{l}\begin{array}{c}\text { Atome } \mathrm{Ca} \\
\text { aufgelöst }\end{array} \\
\frac{\mathrm{Mol.} \mathrm{P}_{2} \mathrm{O}_{\tilde{j}}}{\text { aufgelöst }}\end{array}$ & $\mathrm{G} \cdot \mathrm{H} \times 10^{\circ}$ \\
\hline \multirow{2}{*}{1} & 0 & $1^{\prime} 45^{\prime \prime}$ & 46,0 & 87,7 & \multirow{2}{*}{$4,7: 1$} & 0,16 \\
\hline & 1,12 & $30^{\prime}$ & 56,4 & 93,4 & & 0,14 \\
\hline \multirow{2}{*}{2} & 0 & $1^{\prime} 45^{\prime \prime}$ & 49,2 & 92,6 & \multirow{2}{*}{$4,5: 1$} & - \\
\hline & 2,24 & $\infty$ & 62,0 & 99,8 & & - \\
\hline
\end{tabular}

Geht man davon aus, daß der an das Casein gebundene Kalk eine Rolle spielt, dann ist die Verzögerung des Gerinnens durch obige Tabelle auf einfache Weise vollständig erklärt.

4. Durch Verdünnung der Milch wird die Gerinnungszeit verlängert.

Schon Hammarsten hat in seiner bereits oben zitierten ausführlichen Abhandlung Zahlen mitgeteilt, um zu zeigen, wie die Gerinnungszeit von der Verdünnung mit Wasser abhängt. Je mehr Wasser man zusetzt, desto langsamer koaguliert die Flüssigkeit. Die Erklärung lag auf der Hand: durch die Verdünnung wird die Konzentration der Kalksalze geringer und daher muß die Gerinnung später eintreten.

Nun ist es leicht, zu zeigen, daß noch andere Ursachen für diese Erscheinung angeführt werden können. Aus dem folgenden Versuch z. B. ist ersichtlich, daß bei dem Verdünnen mit Wasser eine Veränderung in bezug auf den Caseinkalk 
vor sich geht. $50 \mathrm{ccm}$ gut gerinnende Milch wurden mit demselben Volumen destillierten Wassers verdünnt, die Mischung sofort in einen Destillierkolben gebracht und bei einer Temperatur von $24-29^{\circ} \mathrm{C}$. ein Volumen Wasser, gleich dem des zugesetzten Wassers, abdestilliert. Das nahm 2 Stunden in Anspruch. Da in der Milch keine Veränderungen stattgefunden hatten, hätte man für die in dem Kolben zurückbleibende Milch dieselbe Gerinnungszeit wie für die frische erwarten können. Gefunden wurde:

Unverdünnte Milch $125^{\prime \prime}$

Verdünnt und darauf abgedampft $243^{\prime \prime}$

Verdünnte Milch $\pm 15^{\prime}$

Während also durch das Abdestillieren des Wassers bei niedriger Temperatur die gelösten Kalksalze wieder auf ihren ursprünglichen Gehalt zurückgebracht sind, gerinnt doch diese Milch halb so schnell wie die unverdünnte. Über die Art der Veränderung kann nichts Sicheres gesagt werden; es ist verlockend, eine teilweise Hydrolyse des Caseinkalks anzunehmen, wodurch also weniger Calcium an Casein gebunden sein würde, während bei dem Verdampfen der ursprüngliche Zustand nicht schnell zurückkehrt, wie auch in sonstigen Fällen wohl wahrgenommen wird. Wegen des eigenartigen Zustandes, in dem der Caseinkalk in der Milch vorkommt, scheint es mir besser, auf dergleichen Betrachtungen, die für normale Lösungen so oft den Weg zur Erklärung von Erscheinungen weisen, nicht zu viel Wert zu legen. Vorläufige Untersuchungen, namentlich mit Bezug auf die Veränderung, die mit der Milch beim Kochen vorgeht, machen es aber wahrscheinlich, daß man es mit einem hydrolytischen Prozeß zu tun hat. Diesem wäre dann auch zum großen Teil das Nichtgerinnen gekochter Milch zuzuschreiben. Ganz übereinstimmend hiermit ist, daß Milch mit hohem H-Ionengehali beim Kochen gerinnbar bleibt. Der Hydrolyse würde dann hier entgegengewirkt. Später hoffe ich hierüber noch das eine oder andere mitteilen zu können.

Daß durch die Verdünnung auf jeden Fall eine Veränderung stattfindet, wodurch die Milch langsamer gerinnt, ist überzeugend aus dem Versuche ersichtlich. 
Ein zweiter Punkt, dem bei der Verdünnung mit Wasser auch noch niemals Rechnung getragen wurde, ist dieser, daß infolge der Vergrößerung der Hydrolyse der gelösten Phosphate der H-Ionengehalt durch die Verdünnung zurückgehen muß, wodurch das Gerinnen träger wird. Daß dies wirklich der Fall ist, geht aus folgenden Zahlen hervor.

$$
\begin{array}{ll}
\text { Milch, unverdünnt: } & \mathrm{C}_{\mathrm{H}}=0,16 \times 10^{-6} \\
\text { Verdünnung } 1: 1: & \left.\mathrm{C}_{\mathrm{N}}=0,10 \times 10-6{ }^{1}\right)
\end{array}
$$

Ein zweiter Faktor also, den man nicht außer acht lassen darf.

Ferner ist die Konzentration des Caseinkalkes von Einfluß. Hierüber hat $\mathrm{Fuld}^{2}$ ) eingehende Untersuchungen angestellt. Auf Grund seiner Versuche über das Gerinnen kam er zu der Meinung, daß die Umsetzungsgeschwindigkeit des Caseins in Paracaseinkalk konstant ist, $d$. $h$. daß die Gerinnungszeit kürzer ausfällt, je nachdem weniger Käsestoff zur Gerinnung vorhanden ist. $\mathrm{Da}$ ich aus meinen Versuchen schließen muß, daß die Konzentration des Caseins beträchtlich die Gerinnungszeit beeinflußt, möge hier eine kurze Übersicht über die Untersuchungen Fulds gegeben werden.

Als erstes Argument wird angeführt, daß es für die Gerinnungszeit gleichgültig ist, ob man eine bestimmte Menge Milch auf einmal mit Lab vermengt oder in zwei Portionen, also so, daß, nachdem das Lab einige Zeit z. B. auf die Hälfte der Milch eingewirkt hat, die andere Hälfte zugegossen wird. Die totale Gerinnungszeit ist ersichtlich in beiden Fällen dieselbe (siehe Tabelle XI).

Wie man sieht, zeigt die dritte Horizontale schon einen großen Unterschied zwischen den berechneten und den gefundenen Werten. Fuld bemerkt daher auch dazu, daß man mit dem Zugießen der Milch zu der Mischung nicht länger warten darf,

1) Die Zahl 0,10 $\times 10^{-6}$ ist sicher noch hoch. Bei der Bestimmung der elektromotorischen Kraft wurde dieselbe NaCl-Konzentration gebraucht wie bei dem Untersuchen der nicht verdünnten Milch; das dadurch auftretende Kontaktpotential verringert den totalen Wert für $E$, wodurch eine etwas zu hohe Ziffer für $\mathrm{C}_{{ }_{\mathrm{H}}}$ gefunden wird.

2) Hofmeisters Beiträge, Bd. II (1902), S. 169. 
Tabelle XI.

$10 \mathrm{ccm}$ Milch gerinnen mit $0,1 \mathrm{ccm} \mathrm{Lab}$ in $32^{1 / 2}$ Sekunden

\begin{tabular}{|c|c|c|c|c|}
\hline $\begin{array}{c}\text { Diese Mischung } \\
\text { steht }\end{array}$ & $\begin{array}{l}\text { Dann wird } \\
\text { zugesetzt }\end{array}$ & $\begin{array}{c}\text { Gerinnt also } \\
\text { nach }\end{array}$ & $\begin{array}{l}\text { Totale } \\
\text { Gef. }\end{array}$ & $\begin{array}{l}\text { angszeit } \\
\text { Ber. }\end{array}$ \\
\hline $5^{\prime \prime}$ & $10 \mathrm{ccm}$ Milch & $62^{\prime \prime}$ & $67^{\prime \prime}$ & $65^{\prime \prime}$ \\
\hline $10^{\prime \prime}$ & 10 & $54 " \prime$ & $54 " \prime$ & $65^{\prime \prime}$ \\
\hline $15^{\prime \prime}$ & $10 \gg$ & $62^{\prime \prime}$ & $77^{\prime \prime}$ & $65^{\prime \prime}$ \\
\hline
\end{tabular}

bis die Hälfte der zu erwartenden Gerinnungszeit verstrichen ist, denn schon früher (15 von den $32 \frac{1}{2}$ Sekunden) tritt eine starke Verzögerung ein. Den Grund hierfür sucht er in einer Umhüllung der Labteilchen, wodurch die später zugesetzte Milch deren Einwirkung entzogen wird. Obwohl nun die Möglichkeit einer solchen Störung zugegeben werden muß, sind doch die Abweichungen derart, daß diese Resultate schwerlich als Argument für eine Annahme dienen können, für die, wie Fuld selbst bemerkt, in der physikalischen Chemie kein zweites Beispiel bekannt ist. ${ }^{1}$ ) Jedoch die Versuche, später noch einmal Lab zuzusetzen, nachdem die Milch durch eine erste Menge Lab schon teilweise umgesetzt war, ergaben ein besseres Resultat, aber gerade hierbei bekomme ich andere Ergebnisse.

Fuld folgert so. Nennen wir die Gerinnungszeit für die erste Menge Lab T, die Zeit nach Zusatz der ersten Portion bis zu der Mischung mit der zweiten Labmenge (die wir der Einfachheit halber als ebenso groß wie die erste annehmen) $t$, dann bekommen wir für die totale Gerinnungszeit $\mathrm{x}$ :

$$
\begin{aligned}
& x=t+\frac{T-t}{2} \\
& \text { oder } x=\frac{t+T}{2}
\end{aligned}
$$

1) 1904 wurde von Armstrong (Proc. Roy. Soc., Bd. LXXIII) zwar gefunden, daß bei sehr hohen Konzentrationen $(10-40 \%)$ die Menge des durch Lactase hydrolysierten Milchzuckers von diesen Konzentrationen unabhängig ist, aber bei Verdünnungen, die mit der Eiweißkonzentration in der Milch vergleichbar sind, schien die Menge unzersetzten Zuckers mit der Konzentration proportional zu sein.

Hoppe-Seyler's Zeitschrift f. physiol. Chemie. LVIII. 
d. h. in der Annahme, daß die Caseinkonzentration auf die Umsetzungsschnelligkeit nicht von Einfluß ist.

Hier folgen seine Resultate.

$10 \mathrm{ccm}$ Milch $+0,1 \mathrm{ccm}$ Lab gerinnen in 36 Sekunden

\begin{tabular}{c|c|c|c|c} 
Die Mischung steht & Dann zugesetzt & $\begin{array}{c}\text { Gerinnt dann } \\
\text { nach }\end{array}$ & Gef. & Ber. \\
\hline $10^{\prime \prime}$ & 0,1 ccm Lab & $13^{\prime \prime}$ & $23^{\prime \prime}$ & $24,5^{\prime \prime}$ \\
$20^{\prime \prime}$ & $0,1, \times$ & $7^{\prime \prime}$ & $27^{\prime \prime}$ & $23^{\prime \prime}$
\end{tabular}

Meine mit der größten Sorgfalt angestellten Versuche ergaben :

1. $20 \mathrm{ccm}$ Milch $+0,5 \mathrm{ccm}$ Lab gerinnen in 310 Sekunden

\begin{tabular}{c|c|c|c|c} 
Die Mischung steht & Dann zugesetzt & $\begin{array}{c}\text { Gerinnt dann } \\
\text { nach }\end{array}$ & Gef. & Ber. \\
\hline $90^{\prime \prime}$ & 0,5 ccm Lab & $153^{\prime \prime}$ & $243^{\prime \prime}$ & $200^{\prime \prime}$ \\
$150^{\prime \prime}$ & $0,5,$, & $106^{\prime \prime}$ & $256^{\prime \prime}$ & $230^{\prime \prime}$
\end{tabular}

2. $20 \mathrm{ccm}$ Milch $+0,5 \mathrm{ccm}$ Lab gerinnen in 233 Sekunden

$90 "|0,5 \mathrm{ccm} \mathrm{Lab}| 105^{\prime \prime}\left|195^{\prime \prime}\right| 161^{\prime \prime}$

3. $20 \mathrm{ccm}$ Milch gerinnen mit $0,5 \mathrm{ccm}$ Lab in 215 Sekunden

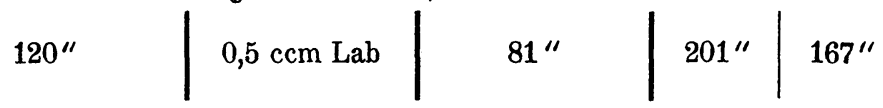

Wie man sieht, besteht hier keine Übereinstimmung zwischen den berechneten und gefundenen Zahlen; die gefundenen Gerinnungszeiten sind beträchtlich größer als die berechneten. Welcher Ursache diese Abweichung von den Resultaten Fulds zuzuschreiben ist, läßt sich ohne nähere Untersuchung nicht sagen, aber gegen seine Methode habe ich dies einzuwenden, daß die beträchtlich große Menge Lab, die er gebraucht, die wirksamen H-Ionen verändern kann (ich fand bei verschiedenen Labmengen darin große Unterschiede), so daß dann das Lab in der ersten Phase in einem andern Medium wirkt als in der zweiten. Aut jeden Fall stimmen meine Zahlen nicht zu der Auffassung Fulds. 
Eine notwendige Folgerung seines Satzes ist ferner, daß für konstante Labkonzentrationen die Gerinnungszeit länger ausfallen müßte, je mehr Casein zu verkäsen ist, $d$. $h$. verdünnte Milch müßte schneller gerinnen als nicht verdünnte, wenn wenigstens durch die Verdünnung selbst keine Störung verursacht wurde. Bei Zusatz von Wasser ist dies wohl der Fall; darum hat Fuld Molke gebraucht, die vorher neutralisiert wurde. Auf diese Weise glückte es ihm, einige Male Gerinnungszeiten zu finden, die der Milchmenge proportional waren. Er gibt folgende Zahlen an:

\section{Tabelle XII.}

$9 \mathrm{ccm}$ Molke $+1 \mathrm{ccm}$ Milch gerinnen mit $0,4 \mathrm{Lab}$ in $2^{\prime \prime}$ ber. $1^{\prime \prime}$

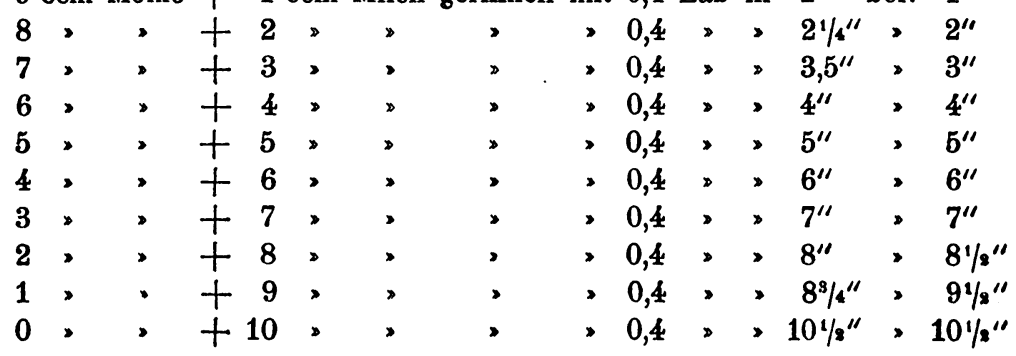

Auf Grund dieser Zahlen sagt Fuld: ${ }^{1}$ )

«Die Neutralisation der Molke bereitet große Schwierigkeiten; die Reaktion der Milch kann doch nicht erreicht werden, da ja eben das Casein entfernt ist. Welchen Indikator man auch benutzen mag, das oben genannte Resultat ist nicht regelmäßig zu erlangen. Möglich, daß die beim Ansäuern (obwohl oft spontan gesäuerte Milch von derselben Kuh diente) und Neutralisieren herbeigeführte Verdünnung mitspielt; wahrscheinlicher ist es, daß die Ausscheidungsbedingungen des Käses, seine Scheinlöslichkeit, das Hindernis darstellt.»

Wie man sieht, drückt Fuld sich hier etwas reserviert aus. Nach allem, was ich vorhin über den Einfluß der HIonen auf das Gerinnen mitgeteilt habe, ist es begreiflich, daß nicht regelmäßig dasselbe Resultat sich ergab, aber zugleich ist ersichtlich, daß es möglich sein muß, solche Zahlen zu finden. Nach meiner Meinung ist aber die Erklärung darin

1) Ebendort, S. 187. 
zu suchen, daß im Verhältnis zu der Milch die zugesetzte Molke viel H-Ionen enthielt (vielleicht auch Kalksalze), so daß für die starken Verdünnungen ein saureres Medium bestand, das bei den weniger starken Verdünnungen durch die Milch teilweise neutralisiert war. Warum für diese Versuche so kurze Gerinnungszeiten gewählt wurden, ist mir nicht verständlich. Daß wirklich die Erklärung der Fuldschen Zahlen in dieser Richtung gesucht werden kann, geht noch deutlicher aus meinen Verdünnungsversuchen hervor, deren Resultate unten mitgeteilt sind.

Schließlich fällt durch meine Untersuchung auch das letzte Argument Fulds für seine Ansicht, die sich auf folgenden Versuch stützt: $50 \mathrm{~g}$ frische Milch verdünnte er mit $100 \mathrm{ccm}$ gesättigter Kochsalzlösung, dann wurde mit einem Überschuß von reinem $\mathrm{NaCl}$ geschüttelt, bei $40^{\circ} \mathrm{C}$. digeriert, das Filter mit gesättigter $\mathrm{NaCl}-L$ Lösung ausgewaschen, der Niederschlag in $30 \mathrm{ccm}$ Wasser suspendiert und vom Bodensatz abgegossen. Von der erhaltenen Flüssigkeit wurden 1, 3, 5 und $7 \mathrm{ccm}$ abgemessen. Alle Flüssigkeit en wurden mit $1 \mathrm{ccm}$ doppelt normaler Baryumnitratlösung behandelt und dann auf $10 \mathrm{ccm}$ aufgefüllt.

\begin{tabular}{|c|c|c|c|}
\hline Casein & $1 \mathrm{ccm}$ & - & Gerinnungszeit \\
\hline 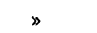 & $3 \%$ & - & » \\
\hline$\Rightarrow$ & 5 . & - & D \\
\hline$D$ & 78 & - & $\triangleright$ \\
\hline
\end{tabular}

Hier setzt er noch hinzu: "Auch durch Verdünnung der Milch mit optimaler Chlorcalciumlösung habe ich hierher gehörige Resultate erhalten.»

Nach dem, was ich bei Punkt 1 mitgeteilt habe, ist es unnötig, besonders darauf hinzuweisen, daß auch dies Argument für die Auffassung, daß die Umsetzungsschnelligkeit von der Caseinkonzentration unabhängig wäre, hinfällig ist.

Aus dem folgenden einfachen Versuch z. B. ist der Einfluß der Konzentration des Caseins ersichtlich. Ein Teil einer Milchprobe wurde durch ein Chamberlandfilter filtriert und mit diesem Filtrat wurde die Milch verdünnt. Durch diese Verdünnung werden also die gelösten Salze nicht geändert, aber die Konzentration der nicht filtrierten Stoffe wird kleiner. 
Tabelle XIII.

\begin{tabular}{c|c|c}
\hline Milch & Serum & T. \\
\hline 10 & 0 & $23^{\prime \prime}$ \\
7,5 & 2,5 & $28^{\prime \prime}$ \\
5,0 & 5,0 & $37^{\prime \prime}$ \\
2,5 & 7,5 & $52^{\prime \prime}$
\end{tabular}

Hierbei ist auch sehr deutlich der Einfluß der H-Ionen, auf den oben hingewiesen wurde, zu sehen. Es macht nämlich einen großen Unterschied aus, ob das Serum direkt, d. h. so, wie es aus dem Filter kommt, für die Verdünnung gebraucht wird, oder nach dem Auspumpen des bei der Filtration hineingepreßten Gases mit einer Quecksilberluftpumpe.

Tabelle XIV.

\begin{tabular}{c|c|c|c}
\hline Milch & Serum & Ausgepumpt & Nicht ausgepumpt \\
\hline 10 & 0 & $133^{\prime \prime}$ & $131^{\prime \prime}$ \\
7,5 & 2,5 & $158^{\prime \prime}$ & $153^{\prime \prime}$ \\
5,0 & 5,0 & $215^{\prime \prime}$ & $184^{\prime \prime}$ \\
2,5 & 7,5 & $311^{\prime \prime}$ & $225^{\prime \prime}$
\end{tabular}

Der Unterschied in der Gerinnungszeit ist beträchtlich und wird um so größer, je mehr Serum zugesetzt wird; wie schon gesagt, sind hierdurch teilweise die Resultate Fulds zu erklären. Daß nicht eine beträchtliche Verminderung der HIonen bei der Verdünnung die Ursache der Verlangsamung ist, geht aus folgender Messung hervor:

$$
\begin{aligned}
& \mathrm{C}_{\mathrm{H}} \text { Milch }-0,15 \times 10^{-6} \\
& \mathrm{C}_{\mathrm{H}} \text { verdünnt 1: } 1-0,13 \times 10-6
\end{aligned}
$$

Aus diesen Verdünnungsversuchen kann geschlossen werden, daß die Gerinnung szeit länger ist, wenn die Caseinkalkkonzentration kleiner ist.

Auch dies wird also zu einer Verlangsamung des Gerinnens der mit Wasser verdünnten Milch beitragen. Bedenkt 
man dabei, daß die Veränderung des osmotischen Druckes noch ein Grund für die Verlangsamung zu sein scheint, ${ }^{1}$ ) dann ist es, alles zusammen genommen, durchaus nicht nötig, die Verminderung in der Konzentration der Kalksalze als die Ursache des Einflusses der Verdünnung mit Wasser anzunehmen. Ich habe jedoch bei diesen Verdünnungsversuchen ein Resultat bekommen, das stark für die Wirkung der löslichen Kalksalze oder Calciumionen spricht und das mit der oben entwickelten Auffassung nicht zu erklären ist. Bei dieser Probe wurde von folgendem Gedankengang ausgegangen. Wenn die Kalksalze, die gelöst sind, keinen Einfluß ausüben, dann muß die Gerinnungszeit von mit gewöhnlichem Serum verdünnter Milch dieselbe sein, als wenn dieselbe Verdünnung durch Oxalatserum hergestellt wird, d. h. Serum von Milch, der etwas Kaliumoxalat zugesetzt wurde, wodurch also ein Teil der Kalksalze niedergeschlagen wird.

Wie aus dem folgenden Versuch hervorgeht, ist dies nicht der Fall.

Der Milch wurde wieder die mit den gelösten Kalksalzen äquivalente Menge Kaliumoxalat zugesetzt und filtriert; von derselben Milch wurde ein Teil filtriert, ohne daß ein Oxalat zugesetzt war.

$1\left\{\begin{array}{lll}5 \text { Milch }+5 \text { ausgepumptes gewöhnliches Serum } & 4^{\prime} 50^{\prime \prime} \\ 5 *+5 & \text { Oxalatserum } & 8^{\prime} 48^{\prime \prime}\end{array}\right.$

$2\left\{5\right.$ Milch +5 ausgepumptes gewöhnliches Serum $120^{\prime \prime}$

$5>+5$ * Oxalatserum $345^{\prime \prime}$

Ammoniumoxalat an Stelle von Kaliumoxalat zum Niederschlagen gebraucht.

$3 \begin{cases}5 \text { Milch }+5 \text { gewöhnliches Serum } & 180^{\prime \prime} \\ 5 & 330^{\prime \prime}\end{cases}$

Der Wasserstoff-Ionengehalt dieser Sera war durchaus derselbe nach Entfernung der aufgelösten Kohlensäure; auch in dem Eiweibgehalt wurde bei dem Kaliumoxalatserum kein Unterschied gefunden. Wie gesagt, es ist mir nicht geglückt, für dieses Resultat eine annehmbare Erklärung zu finden, ohne den Calcium-Ionen einen großen Einfluß auf die Gerinnungszeit zuzuschreiben.

1) Reichel u. Spiro, ebendort. 
Nimmt man diesen an, dann ist der Vorgang nicht anders, als er zu erwarten war; jedoch besteht dann auch hier nicht die Proportionalität zwischen Calcium-Ionen und Gerinnungsgeschwindigkeit. Für das Oxalatserum muß eine nur äußerst geringe Menge Calcium-Ionen angenommen werden, denn die Milch ist vollkommen ungerinnbar, sodaß durch die Verdünnung mit diesem Serum der Calcium-Ionengehalt auf etwas mehr als die Hälfte verringert wird. Das Verhältnis der Gerinnungszeiten weicht aber zu viel von dem Verhältnis $1: 2 \mathrm{ab}$.

Ganz gewiß liegt also hierin ein Argument gegen die Auffassung, zu der alle auf den vorigen Seiten besprochenen Resultate fübrten, aber es muß darauf hingewiesen werden, daß gewöhnliches Serum und Oxalatserum nicht ganz miteinander verglichen werden können, so daß dieses Resultat nicht als ein ausschlaggebender Beweis für die Wirkung der Calcium-Ionen angesehen werden kann. Wenn ich alle die erhaltenen Resultate zusammenstelle, dann sehe ich es nach wie vor als sehr wahrscheinlich an, daß das mehr oder weniger schnelle Präzipitiertwerden des Paracaseinkalks, abgesehen von der Menge Lab und der Temperatur, von dem realen Säuregrad und der Menge Kalk, die durch das Casein gebunden ist, abhängt. Diese hängt zwar wieder zusammen mit den CalciumIonen in der Flüssigkeit und insofern sind diese ohne Zweifel von Bedeutung, aber über die hierbei auftretenden Gleichgewichte, welche wegen der komplizierten Zusammensetzung der Milch etwas verwickelt sind, wissen wir eigentlich sehr wenig, da der eigenartige Zustand, in dem sich der Caseinkalk in der Milch befindet, nicht zuläßt, so ohne weiteres die für Elektrolyte gefundenen Gesetze über das Gleichgewicht auf die Milch anzuwenden. Tabelle VI würde darauf hindeuten, daß bei $\mathrm{Zu}$ satz von H-Ionen der Einfluß der Calcium-Ionen auf die Menge des an Casein gebundenen Kalkes unbedeutend ist.

Bei der Verdünnung von Milch ergeben sich Erscheinungen, die noch auf keine Weise erklärt werden können, z. B. die von Reichel und Spiro ${ }^{1}$ ) wahrgenommene Tatsache, daß bei Verdünnung mit Kochsalzlösung ein großer Unterschied in

1) Ebenda. 
der Gerinnungszeit wahrgenommen wird und zwar bei direkter Bestimmung (unmittelbar nach der Verdünnung) und bei jener, die eine Stunde später ausgeführt wird. ${ }^{1}$ ) Die folgende Tabelle gibt ihre Resultate.

Tabelle XV.

\begin{tabular}{c|c|c}
\hline \multirow{2}{*}{$\%$ NaCl } & \multicolumn{2}{|c}{ T. (in Sekunden) } \\
& Direkt & Nach 1 Stunde \\
\hline 0,5 & 5 & 5 \\
0,9 & 6,5 & 7 \\
1,7 & 9 & 12 \\
2,5 & 12 & 16,5 \\
4,5 & 16,5 & 28,5 \\
6,5 & 18,5 & 38 \\
8,5 & 19,5 & 49
\end{tabular}

Die ausführliche Untersuchung, von der ich hier eine kurze Ubersicht gegeben habe, war nötig, um mit einiger Sicherheit sagen zu können, in welcher Richtung nach der Ursache des Nichtgerinnens der Milch gesucht werden muß. Auf Grund meiner Resultate liegt also die Möglichkeit vor, daß das Nichtgerinnen eine Folge des zu niedrigen Kalkgehaltes der Milch ist, in dem Sinne, daß der Gehalt des an Casein gebundenen Kalkes zu niedrig ist. Die Gesamtkalkbestimmung in einigen Proben $^{2}$ ) Milch ergab ein Resultat, das hiermit vollkommen übereinstimmt, wie aus den folgenden Zahlen hervorgeht.

\begin{tabular}{|c|c|c|c|}
\hline & mg $\mathrm{CaO}$ per $100 \mathrm{ccm}$ Milch & & \\
\hline 1. & 138 & nicht & gerinnend \\
\hline 2. & 137 & » & $»$ \\
\hline 3. & 135 & schlecht & $»$ \\
\hline
\end{tabular}

1) Es wäre interessant, $z u$ untersuchen, ob in diesem Falle vielleicht eine langsame Umsetzung von Na- und Ca-Atomen stattindet, eine Vermehrung der löslichen Kalksalze also auf Kosten vom colloïdalen Kalke. (Bemerkung bei der Korrektur.) Boekhout.

${ }^{2}$ ) Teilweise nicht publizierte Analysen von Ott de Vries und 


\begin{tabular}{|c|c|c|c|}
\hline & mg $\mathrm{CaO}$ per $100 \mathrm{ccm}$ Milch & & \\
\hline 4. & 140 & \multicolumn{2}{|c|}{ nicht gerinnend } \\
\hline б. & 140 & schlecht & $>$ \\
\hline 6. & $115(?)$ & nicht & $\triangleright$ \\
\hline 7. & 140 & nicht & > \\
\hline 8. & 143 & schlecht & $\gg$ \\
\hline 9. & 150 & s & $\triangleright$ \\
\hline 10. & 154 & norm. & $»$ \\
\hline 11. & 154 & $\triangleright$ & > \\
\hline 12. & 146 & > & , \\
\hline 13. & 168 & » & 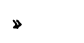 \\
\hline 14. & 161 & $\triangleright$ & $»$ \\
\hline 15. & 155 & , & , \\
\hline 16. & 175 & $»$ & 》 \\
\hline
\end{tabular}

Wie man sieht, ist bis auf eine Ausnahme der Gehalt der normal gerinnenden Milch an Kalk beträchtlich höher als der der nicht gerinnenden Milch. Auf diese eingangs gestellte Frage kann also geantwortet werden:

Die Ursache des Nichtgerinnens der Milch liegt im allgemeinen an dem Kalkmangel in der Milch; sehr wahrscheinlich ist dann die an Casein gebundene Menge zu gering, um die Koagulation hervorzubringen.

Interessant ist, im Zusammenhang damit, noch das Resultat, das bei Verabreichung von phosphorsaurem Kalk (Biphosphat) an ein Tier in der mit der «Reichslandw. Versuchsstation * verbundenen "Versuchswirtschaft " erzielt wurde. Diese Kuh lieferte regelmäßig nicht gerinnende Milch. Durch Verabreichen von $50 \mathrm{~g}$ Biphosphat pro Tag gerann nach 2 Tagen die Milch in 70" gegen 60" bei einer Probe gemengter Milch, d. h. die Milch gerann ungefähr normal und blieb so, solange der phosphorsaure Kalk dem Tiere gegeben wurde. Ein aus \pm 201 dieser Milch zubereiteter Käse war nach 4 Wochen sehr schlecht; das Resultat einer zweiten und dritten Zubereitung war sehr günstig. 
Als kein Futterkalk mehr gegeben wurde, hatte nach drei Tagen die Gerinnungszeit wieder stark zugenommen, während der darauf folgenden Tage blieb die Milch gerinnbar, wenn auch nur schlecht.

Bei einer nicht trächtigen Kuh, die in der letzten Woche der Lactationsperiode nicht gerinnende Milch lieferte, gab phosphorsaurer Kalk kein Resultat.

\section{Zusammenfassung.}

Der Zweck dieser Untersuchungen war, den Grund dafür, daß die Milch mancher Kühe nicht gerinnt, zu finden.

Es wurde darauf hingewiesen, daß man bei der Milch zwischen dem titrierten (potenziellen Säuregrad) und dem wirklichen (aktuellen) Säuregrad, d. h. der Wasserstoff-Ionenkonzentration unterscheiden muß. Durch elektrische Meßmethoden wurde der letztere bestimmt. Die gefundenen Werte liegen zwischen 0,14 und $0,32 \times 10^{-6}$ normal. Für nicht gerinnende Milch wurde 0,16 und $0,22 \times 10^{-6}$ gefunden. Mangel an $\mathrm{H}-$ Ionen war also nicht die Ursache.

Diese Messungen ermöglichten es, den Zusammenhang zwischen Wasserstoff-Ionen und Gerinnungszeit zu finden. Di e Gerinnungszeit ist umgekehrt proportional den Wasserstoff-Ionen.

Mit diesen Resultaten war es wieder möglich, den Einfluß der löslichen Kalksalze aufzufinden. Mit großer Wahrscheinlichkeit wurde festgestellt, daß diese keinen oder beinahe keinen Einfluß auf die Gerinnungsgeschwindigkeit ausüben; dagegen machen es die Ergebnisse wahrscheinlich, daß die Menge des an Casein gebundenen Kalkes für das Koagulieren maßgebend ist. Diese Auffassung, die von der üblichen, daß die löslichen Kalksalze eine große Bedeutung dafür haben, abweicht, machte eine ausführliche Untersuchung der Argumente, die gewöhnlich für diese Hypothese angeführt werden, erwünscht.

Gefunden wurde:

1. Bei Zusatz von Chlorcalcium zu Milch bleibt nur $\pm 50 \%$ des zugesetzten Salzes aufgelöst, unabhängig von der Konzentration der Lösung. Für extrem hohe Konzentrationen $(<2 \%$ 
werden keine Ca-Ionen mehr gebunden. Daß bei diesen Konzentrationen das Chlorcalcium doch noch beschleunigend auf das Gerinnen einwirkt, kann durch die Erscheinung erklärt werden, daß durch den Zusatz dieses Salzes der WasserstoffIonengehalt beträchtlich vermehrt wird.

2. Die Dissoziation der Kalksalze in der Milch ist sehr gering; auf jeden Fall geringer als 12\%.

3. Durch Zusatz löslicher Oxalate zu Milch werden nicht an erster Stelle die normal gelösten Kalksalze niedergeschlagen, wie man annimmt, sondern hauptsächlich die Salze, welche sich in Pseudolösung befinden. Bei Milch mit $50 \mathrm{mg}$ $\mathrm{CaO}$ per $100 \mathrm{ccm}$ Serum wurden bei Zusatz der hiermit äquivalenten Menge Kaliumoxalat nur $12 \mathrm{mg}$ präzipitiert. Diese Milch war vollkommen ungerinnbar. Durch Chlorcalcium konnte sie regeneriert werden, obwohl der Gehalt an löslichen Kalksalzen beinahe nicht größer geworden war $(40 \mathrm{mg}$ an Stelle von $39 \mathrm{mg}$ per $100 \mathrm{ccm}$ Serum).

4. Daß lösliche Citrate das Gerinnen verlangsamen oder aufheben, wird dem Niederschlag der gelösten Kalksalze als Calciumcitrat zugeschrieben. Der Versuch lehrt aber das Gegenteil, die kolloidalen Kalksalze werden durch lösliche Citrate gelöst, sodaß der Gehalt an löslichen Kalksalzen sehr steigt, während doch die Milch ungerinnbar wird. Hierbei wurde noch gefunden, daß durch Kaliumcitrat ein Teil des an Casein gebundenen Kalkes sich löst, sodaß auch dieses Resultat vollkommen mit der hier entwickelten Auffassung übereinstimmt.

5. Gezeigt wurde, daß die Verlangsamung im Gerinnen, welche bei der Mischung der. Milch mit Wasser wahrgenommen wird und die man gewöhnlich der Verdünnung der Kalksalze zuschreibt, ebenso gut durch vier Vorgänge, die alle in der Richtung auf langsameres Gerinnen sich geltend machen und die unter Punkt 4 besprochen sind, erklärt werden kann. Ferner wurde darauf hingewiesen, daß man auf Verdünnungsproben mit Molke keinen großen Wert legen kann, weil dabei nicht der Einfluß, der durch kleine Änderungen in dem Wasserstoff-Ionengehalt zu Wege gebracht wird, beachtet ist. Die von mir beobachtete Tatsache, daß Milch, die 
mit Oxalatserum verdünnt wurde, langsamer gerinnt als bei Verwendung von normalem Serum, habe ich nicht erklären können.

Die Ursache des Nichtgerinnens der Milch wurde also schließlich in dem Mangel an Kalk, und zwar an kolloidalem Kalk, gesucht. Bei 16 Proben Milch, von denen acht nicht oder sehr schwer gerannen, wurde der Kalkgehalt der gut gerinnenden Milch deutlich höher befunden als bei den übrigen Proben.

Eine Kuh in der hiesigen mit der Untersuchungsstation verbundenen "Versuchswirtschaft», die regelmäßig nicht gerinnende Milch lieferte, hatte bei täglicher Verabreichung von $50 \mathrm{~g}$ phosphorsaurem Kalk (Biphosphat) nach drei Tagen eine beinahe normal gerinnende Milch.

Reichslandw. Versuchsstation, Hoorn. Juni 1908. 